\title{
Green Circular Development of the Qingba Mountain Area
}

\author{
Gaorui Lin, Jingwen Feng, Zeyang Miao, Xiaohui Yu* \\ School of Architecture, Chang'an University, Xi'an 710061, China
}

Corresponding Author Email: yuxiaohui@chd.edu.cn

https://doi.org/10.18280/ijdne.150309

Received: 10 January 2020

Accepted: 21 March 2020

\section{Keywords:}

green circular $(G C)$ development, the Qinba Mountain Area (QMA), green development, circular economy

\begin{abstract}
With the proliferation of green and low-carbon development, China has made green cyclical (GC) development the key strategy for the transition of development model. This paper firstly analyses the connotations of green development and circular economy, and summarizes the basic features of the concept of the GC development. Based on the features of the Qingba Mountain Area (QMA), the authors set up a four-level (enterpriseindustry-region-society) support system for the GC development in this ecological area, and then constructed a GC development model consisting of three sub-models: the crossindustry sub-model, the urban-rural sub-model, and the cross-regional sub-model. Finally, the three sub-models were combined into the compound socioeconomic system in the QMA. The research findings provide effective reference for the economic development in ecological areas.
\end{abstract}

\section{INTRODUCTION}

In recent years, many countries started to pursue green and low-carbon development, and implement the green new policy, under the effects of global economic recovery and climate change. In 2013, China defined green and low-carbon circular development as the primary strategy for urbanization. In other words, China has made green circular (GC) development a top priority in the transition of the development model.

In ecology, the urban and rural construction has an important impact on environmental changes [1]. So far, many theories and models have been developed on the low-carbon development of urban and rural areas. Most of them focus on the development of low-carbon eco-cities, namely, Berkeley and Copenhagen [2,3]. The trend and strategies of eco-cities $[4,5]$ have also been studied in China, shedding important new light on urban development in ecological areas.

Circular economy is one of the three basic frameworks for eco-city construction [6]. Since the 1990s, this concept has been introduced to urban planning and development. For example, Japan promoted the construction of circular urban agglomerations and the circular society [7], aiming to realize zero emissions. Many regions in China, including southern Jiangsu, Shanghai, Liaoning, and Guiyang, also pursued urban transform through the development of circular economy [8,9].

The Qingba Mountain Area (QMA), an important ecological area and water conservation area in China, covers the Qinling Mountains, the Daba Mountain, and the adjacent areas. This area is characterized by a fragile and sensitive ecoenvironment, as well as a heavy presence of extreme poverty. There is an outstanding contradiction between socioeconomic development and eco-environment. In 2010, the central route of the South-to-North Water Diversion Project passed through this area, highlighting the importance of ecological protection in this area to the regional eco-balance and the national ecosecurity. Therefore, the QMA faces two important tasks: ecological protection, and poverty alleviation.

Over the years, many scholars have studied the GC development of urban and rural areas in the QMA, which is an important ecological region in China. The existing studies mainly focus on the green development policies [10], the spatial pattern of villages in watersheds [11], the spatial form of cities [12], and the ecological landscape [13]. However, there is no report that deals with the GC-based urban and rural development in poor ecological areas of the QMA.

Based on the connotations of green development and circular economy, this paper develops a four-level (enterpriseindustry-region-society) support system for the GC development of the QMA, builds a three-dimensional GC development model, and finally creates a compound socioeconomic system in the QMA. The research results provide effective reference for the GC development in underdeveloped ecological areas in China.

\section{PRELIMINARIES}

\subsection{Green development}

The concept of green development stems from the reflection on traditional industrial civilization. In 2002, the United Nations Development Programme (UNDP) issued the China Human Development Report 2002: Making Green Development a Choice. As mentioned in the Report, green development is a people-oriented approach to sustainable development that emphasizes the unity and harmony between economic growth and environmental protection. Since the 1960s, the concept of green development, originally focusing on the governance and promotion of the output and input, has evolved in three stages (Table 1), becoming increasingly systematic and comprehensive. 
Table 1. The evolutionary stages of green development

\begin{tabular}{|c|c|c|c|c|}
\hline Year & Representative works & Theme & Evolutionary stage & Connotation \\
\hline 1962 & Rachel Carson, Silent Spring & $\begin{array}{l}\text { Reflecting on the environmental damage caused } \\
\text { by industrial civilization }\end{array}$ & \multirow{2}{*}{$\begin{array}{l}\text { Terminal treatment } \\
\text { of environmental } \\
\text { pollution }\end{array}$} & \multirow{2}{*}{$\begin{array}{l}\text { Emissions control } \\
\text { on the output side }\end{array}$} \\
\hline 1972 & $\begin{array}{c}\text { Club of Rome, The Limits to } \\
\text { Growth }\end{array}$ & $\begin{array}{l}\text { Questioning the high-consumption and high- } \\
\text { pollution growth model }\end{array}$ & & \\
\hline 1987 & $\begin{array}{l}\text { World Commission on } \\
\text { Environment and Development, } \\
\text { Our Common Future }\end{array}$ & $\begin{array}{l}\text { Making effective use of resources and reducing } \\
\text { pollution emissions through the development } \\
\text { and effective use of new resources }\end{array}$ & \multirow{2}{*}{$\begin{array}{l}\text { Effective use of } \\
\text { resources and } \\
\text { reduction of } \\
\text { pollution emissions }\end{array}$} & \multirow{2}{*}{$\begin{array}{l}\text { Efficiency } \\
\text { improvement on } \\
\text { the input side }\end{array}$} \\
\hline 1989 & $\begin{array}{c}\text { David W. Pearce, Blueprint for a } \\
\text { Green Economy }\end{array}$ & $\begin{array}{c}\text { Unifying economic development with } \\
\text { environmental protection through the } \\
\text { evaluation of resources and environmental } \\
\text { products/services }\end{array}$ & & \\
\hline 2002 & $\begin{array}{l}\text { UNDP, China Human Development } \\
\text { Report 2002: Making Green } \\
\text { Development a Choice }\end{array}$ & $\begin{array}{l}\text { Defining green development as a people- } \\
\text { oriented approach to sustainable development }\end{array}$ & \multirow{3}{*}{$\begin{array}{l}\text { Comprehensive } \\
\text { green development, } \\
\text { green economy, and } \\
\text { transform of } \\
\text { development model }\end{array}$} & \multirow{3}{*}{$\begin{array}{l}\text { Systematic, } \\
\text { overall } \\
\text { development }\end{array}$} \\
\hline 2008 & $\begin{array}{l}\text { United Nations Environment } \\
\text { Programme (UNEP), Global Green } \\
\text { New Deal }\end{array}$ & $\begin{array}{l}\text { Shifting the focus global economic } \\
\text { development onto clean energy technologies } \\
\text { and natural infrastructure improvement }\end{array}$ & & \\
\hline 2012 & $\begin{array}{l}\text { Earth Summit 2012, Green } \\
\text { Economy and The Future We Want }\end{array}$ & Implementing green transform in poor areas & & \\
\hline
\end{tabular}

\subsection{Circular economy theory}

Circular economy, as a result of the reflection on the traditional development model, deepens the understanding of the relationship between man and nature [14]. After decades of research, the circular economy theory expands the $3 \mathrm{R}$ principle (reduction, reuse and recycling), which was proposed in the $1980 \mathrm{~s}$, to $4 \mathrm{R}, 5 \mathrm{R}$ and even $6 \mathrm{R}$. The expansion from $3 \mathrm{R}$ to $6 \mathrm{R}$ carries the following features:

(1) Establish an innovative theory and methodology that conform to the operating rules of the circular economy, providing a good guidance on the development of the circular economy.

(2) Improve the operating efficiency and popularity of the circular economy model through economic analysis.

(3) Explore the internal laws and trends of regional circular economy through long-term analysis, and formulate relevant strategies and policies.

(4) Analyse the operations of circular economy from multiple angles, such as market, technology, planning, and law, and enrich the contents of circular economy.

(5) Promote the exchange and integration between the circular economy and relevant disciplines, and construct a well-established discipline system of circular economy.

\subsection{Connotation of GC development}

Green development and circular economy are critical to the transform of the traditional resource-extensive model, which emerged and expanded with industrialization, towards the sustainable economic model [15].

Green development seeks for a model or path that increases material wealth without compromising the quality of the ecoenvironment [16] and focuses on the sustainability and health of the development model. Hailed as a novel economic growth model, circular economy aims to reduce material consumption and improve the eco-environment, while maintaining a relatively high rate of economic growth, and also solve the contradiction between economic growth and external constraints (e.g. resource and environment). Focusing on material efficiency, safety and recycling, modern circular economy model can work in synergy with green development [17].
Figure 1 and Table 2 explain the close correlation between circular economy and green development: green development is the goal of circular economy, while circular economy is an important path towards green development [18].

Table 2. The relationship between green development and circular economy

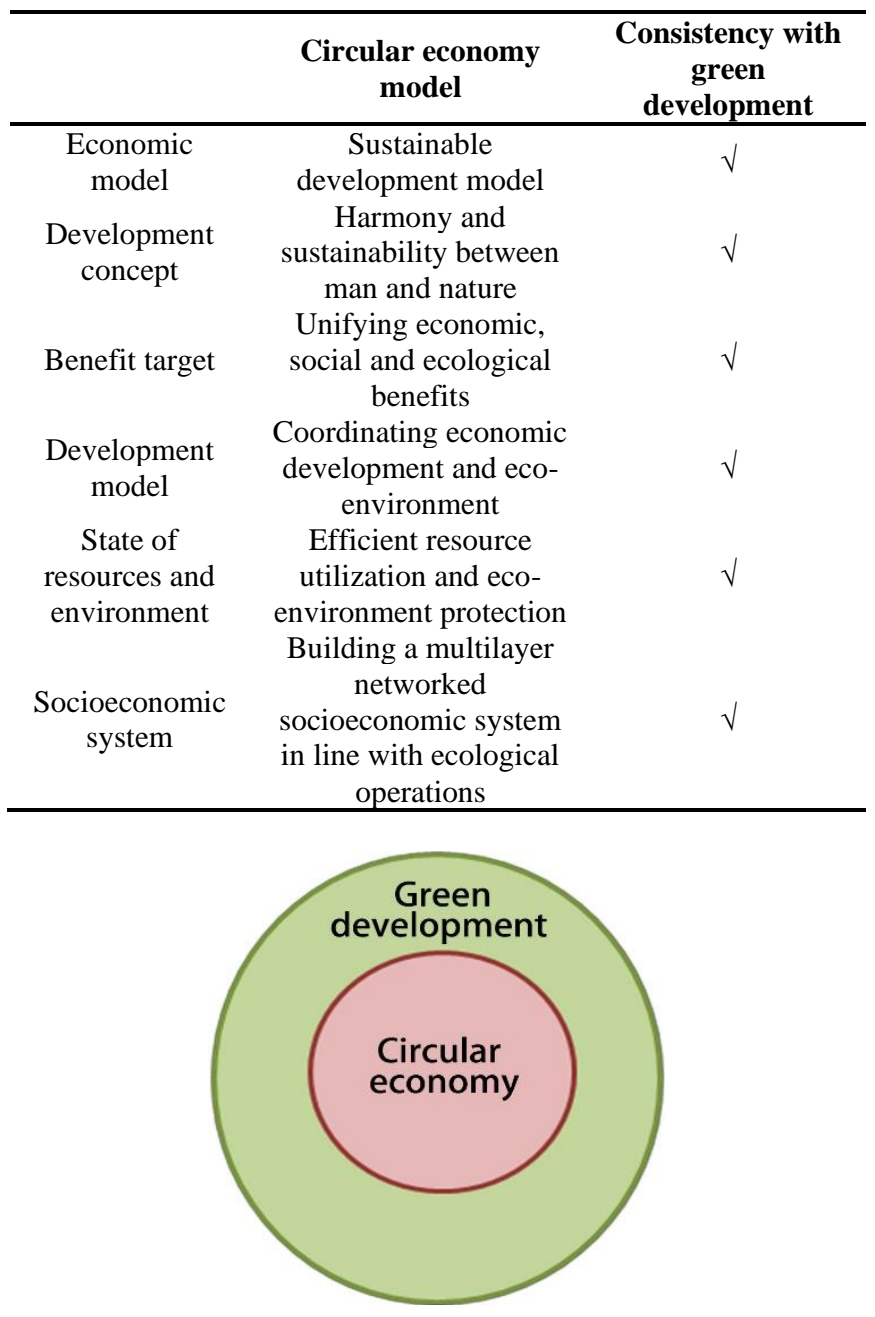

Figure 1. The relative position between green development and circular economy 
Based on the above correlation between green development and circular economy, the GC development was defined as a development model relying on circular economy to achieve green development of the whole society, and pursue sustainable development under the constraints of ecoenvironment capacity and resource carrying capacity.

There are two defining features of the GC development: a system-level circular economy model, and the balance between environment protection and economic growth.

(1) Compared with the traditional economic model, the GC development transforms materials in multiple cycles rather than let them flow linearly. The key of the GC development lies in building a society of circular economy on the level of cities and regions, rather than that on the level of individual enterprises or enterprise groups.

(2) Besides economic growth, the GC development attempts to reduce resource consumption and control pollutant emissions. Under the GC development model, the material needs of economic growth are determined, and the material consumption per unit of growth is lowered to improve the ecological efficiency of economic development.

\subsection{Modelling of GC development}

Drawing on the application of circular economy, the GC development can be modelled based on the industry type or the circulation level.

\subsubsection{GC development model based on industry type}

The GC development model reflects the transform of the entire process of economic activities, which starts from production and ends at consumption. Based on industry type, the model can be divided into the GC industrial model, the GC agricultural model, and the GC industrial-agricultural mixed model.

The GC industrial model extends the production chain through the following operations: sorting out the material circulation between various processes in the enterprise, maximizing the use of renewable materials, and improving the durability of products.

The GC agriculture model tries to reduce waste and pollutant emissions through efficient use and recycling of resources. To modernize agricultural production (i.e. realize efficient and environmentally friendly agricultural production), this model strives to extend and upgrade the industrial chain based on technical progress and management optimization.

The GC industrial-agricultural mixed model couples agriculture with industry by extending the agricultural industry chain and integrating multiple different models.

To sum up, the GC development models based on a single industry mainly extends the industrial chain in the organization of economic activities, thereby achieving the circulation of materials. Meanwhile, the GC development model based on mixed industries horizontally expands the industrial chain to make effective use of materials.

Note that the link between infrastructure and industry has a great impact on the GC mixed model. To recycle materials and minimize emissions, the processed materials should be combined with enterprises in infrastructure construction.

However, most of the existing GC mixed models only take account of the horizontal link of industry and agriculture, failing to consider the circular link between the tertiary industry (especially the service industry) and the primary and secondary industries. Therefore, it is very meaningful to include the tertiary industry into the GC development model.

\subsubsection{GC development model based on circulation level}

The GC development spans across multiple levels rather than focus on a single economic behaviour or the transform between industries. Based on circulation level, the GC development model falls into four types: from bottom to the top, there are the enterprise GC model, the enterprise group (industrial park) GC model, the social consumption and emissions GC model, and the circular social GC model.

Together, the four types of models demonstrate the systematic and holistic nature of the GC development in actual application. Each type of model has its unique emphasis and inherent logic. Judging by hierarchy, the enterprise GC model lays the foundation, the enterprise group GC model lies at the core, the social consumption and emissions GC model provides a necessary link, and the circular social GC model sets the strategy of the GC development, respectively.

For the GC development system, the models on different levels are relatively independent from each other. On each level, the key industries, enterprises, and cities are the core elements, serving as the links or nodes in the system. The GC development model based on circulation level stresses on circular urban agglomerations and circular urban-rural integration, marking an important direction for promotion of circular social systems.

\section{THE GC DEVELOPMENT OF THE QMA}

\subsection{Overview of the QMA}

\subsubsection{Scope}

The QMA belongs to the Qinling-Dabie orogenic belt, which encompasses the Qinling Mountains, the Daba Mountain, the Dabie Mountain, and the northern part of the Jishi Mountain. Located at the geographical centre of China, the QMA covers two mountain ranges (the Qinling Mountains, and the Daba Mountain), and spans across six provincial administrative regions (Shaanxi, Sichuan, Chongqing, Henan, Hubei, and Gansu). There are a total of 22 cities and 122 counties across this $311,200 \mathrm{~km}^{2}$ area. At the end of 2016, the total population in the QMA was 63.39 million. Figures 2-4 and Table 3 provide the basic situation of the QMA.

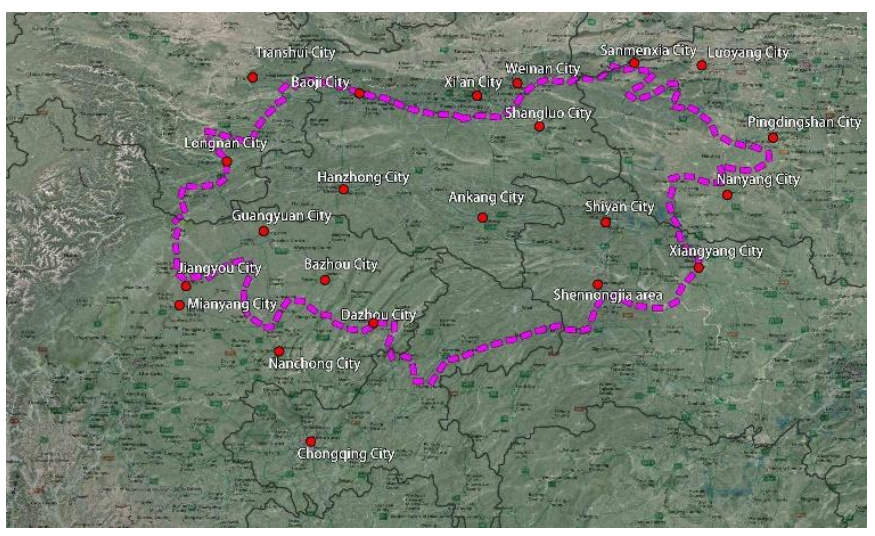

Figure 2. The scope of the QMA 


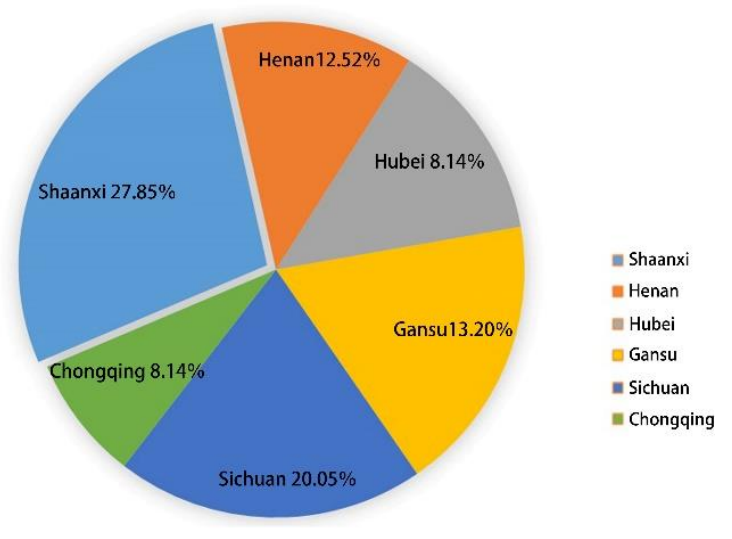

Figure 3. The area ratios of provincial administrative regions in the QMA

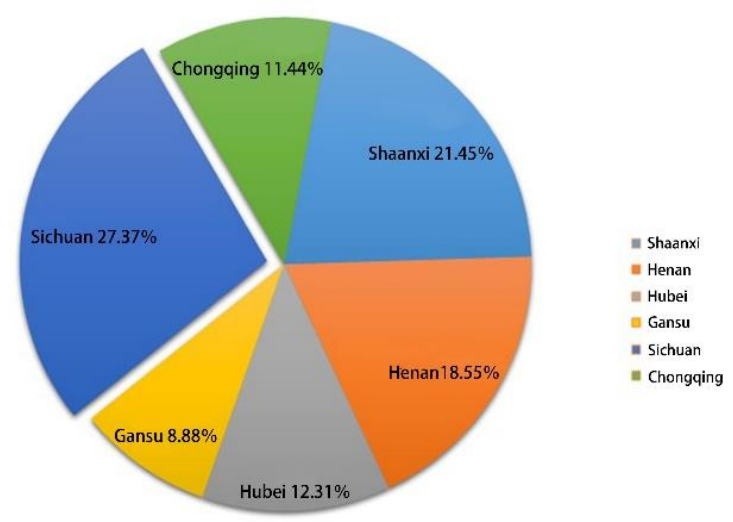

Figure 4. The population ratios of provincial administrative regions in the QMA

Table 3. Administrative regions in the QMA

\begin{tabular}{cccccc}
\hline Provincial administrative regions & $\begin{array}{c}\text { Area } \\
\left(10,000 \mathrm{~km}^{2}\right)\end{array}$ & Area ratio $(\%)$ & Population $(10,000$ persons) & Population ratio (\%) & Cities (counties)* \\
\hline Shaanxi & 8.6903 & 27.85 & 1,360 & 21.45 & 6 cities \\
Henan & 4.0119 & 12.52 & 1,176 & 18.55 & 4 cities \\
Hubei & 4.1185 & 13.20 & 780 & 12.31 & 2 cities, 1 county \\
Gansu & 5.6624 & 18.14 & 563 & 8.88 & 4 cities \\
Sichuan & 6.1846 & 20.05 & 1,735 & 27.37 & 5 cities \\
Chongqing & 2.5410 & 8.14 & 725 & 11.44 & 7 counties \\
Total & 31.2087 & 100.00 & 6,339 & 100.00 & \\
\hline
\end{tabular}

Note: *In this column, the number of counties within the administrative regions of cities is not listed separately.

\subsubsection{Location features}

The QMA stands at a strategic location in China (Figure 5). Apart from being the origin of the Silk Road Economic Belt, this area links up two major cities (i.e. Chongqing and Wuhan) of the Yangtze River Economic Belt, and radiates the Maritime Silk Road. There are five huge urban clusters in the QMA, whose scope of influence overlaps each other. Overall, the QMA connects the inland of China with the Silk Roads, setting an important stage for the Belt and Road Initiative.

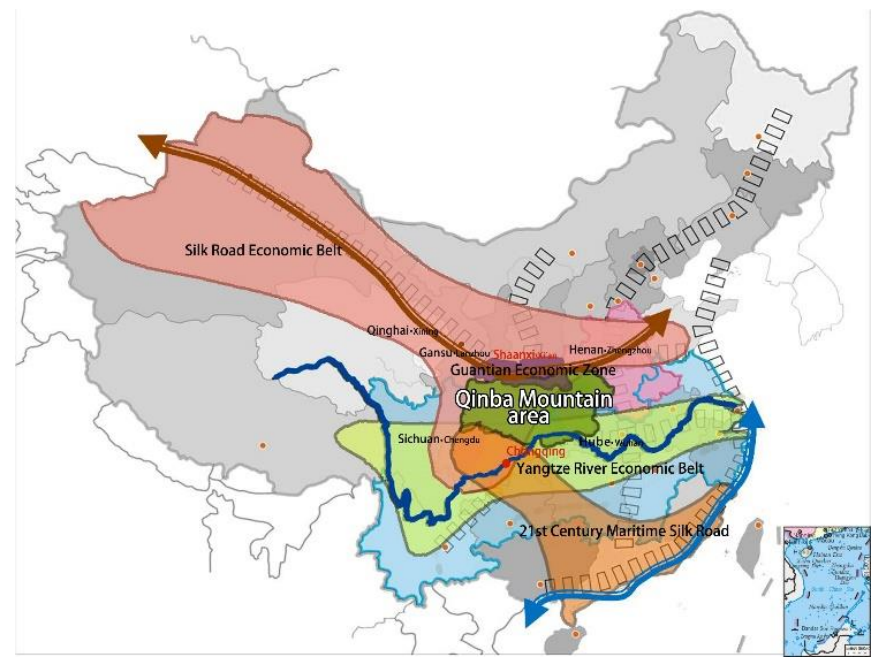

Figure 5. The location features of the QMA

\subsubsection{Resource features}

The QMA is an important ecological area in China, in terms of water conservation and biodiversity. There are developed water systems and abundant runoffs in this area, which stretches across the basins of the Yangtze River, the Yellow
River, and the Huaihe River. Besides, the QMA is where the central route of the South-to-North Water Diversion Project starts. Danjiangkou Reservoir, the water source of that route, has a total annual flow of 38.8 billion $\mathrm{m}^{3}$.

With an average forest coverage of $57.3 \%$, the QMA is home to more than 6,000 kinds of animals and plants, accounting for $75 \%$ of the national total. As a result, this area is the largest biological gene bank, and one of the 17 important biodiversity functional areas in China. The QMA is also rich in mineral resources: 60 types of minerals have been found, surpassing $40 \%$ of the national total.

\subsubsection{Socioeconomic features}

In May 2012, China promulgated the Plan for the Development and Poverty Alleviation in the QMA (2011-2020), listing the QMA as a region of contiguous poor areas. According to the statistics released by local governments, the 91 non-mountainous counties in the QMA have a total urban population of 14.6718 million, that is, 161,200persons/county. The county-level urbanization rate falls in the $30-40 \%$ level. Meanwhile, the urbanization rate of the mountainous counties in this area is $32.5 \%$, much lower than the national average.

\subsection{The GC development model of the QMA}

The preceding subsection shows that the QMA generally faces a backward social economy and an urgent need to protect the ecology. Hence, the GC development of the QMA should be modelled based on the evolution direction of the GC development: from bottom to top, and from simple system to complex system.

Under this principle, the four supports of the GC development of the QMA were identified (Figure 6): enterprise, industry, region, and society. Based on these 
supports and the basic situation of the QMA, three interactive sub-models were constructed for the GC development of the QMA, namely, the cross-industry sub-model, the urban-rural sub-model, and the cross-regional sub-model, which work together to mimic the compound socioeconomic system of the study area.

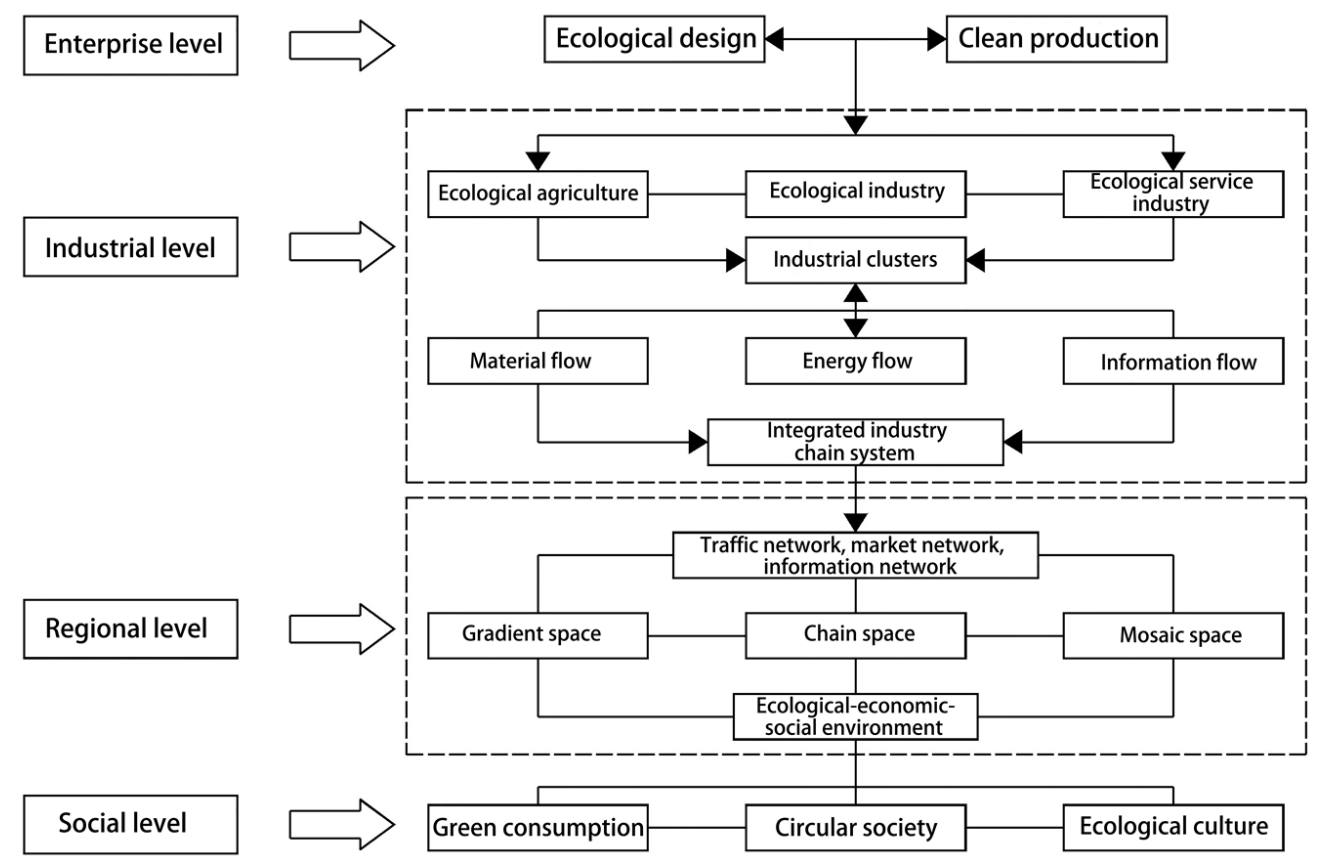

Figure 6. The support system of the GC development of the QMA

\begin{tabular}{|c|c|c|c|c|c|c|c|c|c|c|c|c|c|c|c|c|c|}
\hline \multicolumn{3}{|c|}{$\begin{array}{l}\text { Human resources } \\
\text { services }\end{array}$} & \multicolumn{3}{|c|}{$\begin{array}{c}\text { Technology transfer } \\
\text { services }\end{array}$} & \multicolumn{3}{|c|}{$\begin{array}{l}\text { Financial capital } \\
\text { services }\end{array}$} & \multicolumn{3}{|c|}{$\begin{array}{l}\text { Financial legal } \\
\text { services }\end{array}$} & \multicolumn{3}{|c|}{$\begin{array}{c}\text { Industry association } \\
\text { services }\end{array}$} & \multicolumn{3}{|c|}{$\begin{array}{l}\text { Information mana- } \\
\text { gement services }\end{array}$} \\
\hline 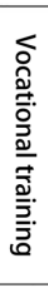 & 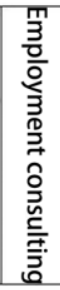 & 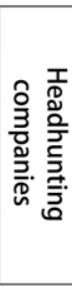 & 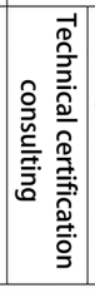 & 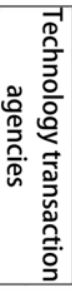 & 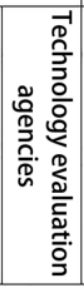 & 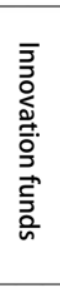 & 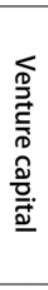 & 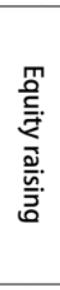 & 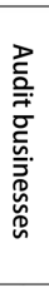 & 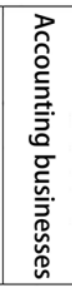 & 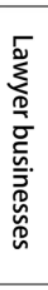 & 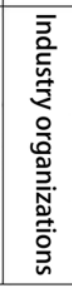 & 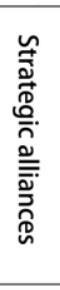 & 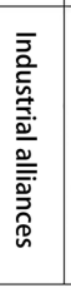 & 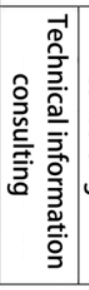 & 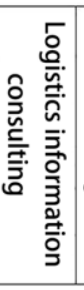 & 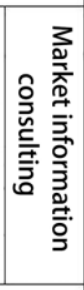 \\
\hline \multicolumn{18}{|c|}{ Producer services } \\
\hline \multicolumn{3}{|c|}{$\begin{array}{l}\text { Improvement of } \\
\text { production factor } \\
\text { conditions }\end{array}$} & \multicolumn{6}{|c|}{$\begin{array}{l}\text { Upgrading of corporate strategy } \\
\text { and competition background }\end{array}$} & \multicolumn{6}{|c|}{$\begin{array}{l}\text { Improvement of related } \\
\text { and supporting industries }\end{array}$} & \multicolumn{3}{|c|}{$\begin{array}{l}\text { Improvement of } \\
\text { demand conditions }\end{array}$} \\
\hline
\end{tabular}

Figure 7. The development pattern of productive service industries

\begin{tabular}{|c|c|c|c|c|c|c|c|c|c|c|c|c|c|c|c|c|}
\hline \multicolumn{2}{|c|}{$\begin{array}{l}\text { Public education } \\
\text { services }\end{array}$} & \multicolumn{3}{|c|}{$\begin{array}{l}\text { Public health } \\
\text { services }\end{array}$} & \multicolumn{3}{|c|}{$\begin{array}{l}\text { Public cultural } \\
\text { services }\end{array}$} & \multicolumn{3}{|c|}{$\begin{array}{l}\text { Public sports } \\
\text { services }\end{array}$} & \multicolumn{3}{|c|}{$\begin{array}{c}\text { Public employment } \\
\text { services }\end{array}$} & \multicolumn{3}{|c|}{$\begin{array}{c}\text { Social security } \\
\text { services }\end{array}$} \\
\hline Child care & 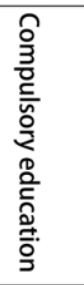 & 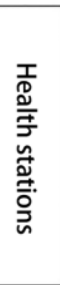 & 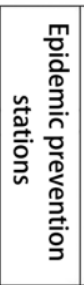 & 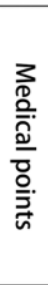 & 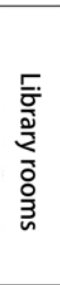 & 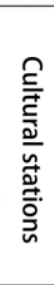 & 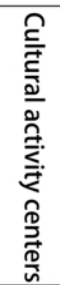 & 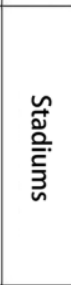 & 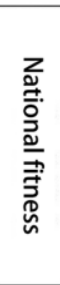 & 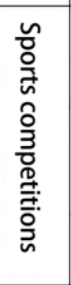 & 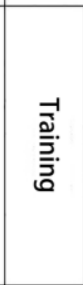 & 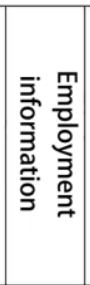 & 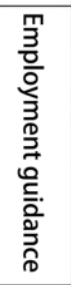 & 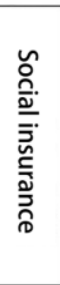 & 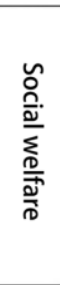 & 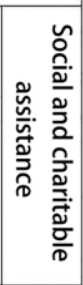 \\
\hline \multicolumn{17}{|c|}{ Public service system } \\
\hline \multicolumn{5}{|c|}{$\begin{array}{l}\text { Guarantee of basic survivability } \\
\text { public service conditions }\end{array}$} & \multicolumn{3}{|c|}{$\begin{array}{l}\text { Basic service } \\
\text { guarantee for } \\
\text { public safety }\end{array}$} & \multicolumn{3}{|c|}{$\begin{array}{l}\text { Promotion of basic } \\
\text { public environ- } \\
\text { mental services }\end{array}$} & \multicolumn{6}{|c|}{$\begin{array}{c}\text { Self-development } \\
\text { basic service construction }\end{array}$} \\
\hline
\end{tabular}

Figure 8. The development pattern of the public service system 


\subsubsection{Cross-industry sub-model}

The cross-industry sub-model emphasizes the symbiosis and circulation within and between industries, which can be achieved through the extension of the industrial chain. During regional economic growth, the value of the industrial chain is increased, as the industry climbs up the value chain according to the spatial layout of resources. That is, the industry is upgraded and transformed, resulting in organizational renewal [19]. In return, the industrial chain exerts a lasting effect on the spatial layout through economic zoning, location advantages, etc.

(1) Basic trinity model

Considering the industrial structure in urban and rural areas, the trinity model was introduced to illustrate the GC development of the QMA. This basic model reveals the role of the value chain in the extension of the industrial chain, and highlights the state and role of service industry in the GC development. Both the government and the public are involved in service industry. This industry reorganizes the society and people, and reshapes the spatial layout of resources, contributing to the goal of the GC development.

(2) Horizontal and vertical industrial chains

The horizontal and vertical industrial chains were conceptualized based on the trinity model. The horizontal industrial chain seeks to boost industrial development by improving the transport conditions: creating a transport network that combines multiple transport models, building a high-speed information network, and promoting the integration between production, logistics and information (e.g. streamlining the physical flow of products and setting up distribution centres).

To increase the added value of products, the vertical industrial chain is extended vertically to relevant fields, including derivative product processing, material recovery, product packaging, and sales planning.

(3) Coupling and coordination of secondary and tertiary industries

The service industry offers a point of breakthrough for industrial growth. The development of the service industry helps to accelerate the upgrading of industrial structure, and reshape and renovate regional functions.

The productive service industry acts as a social intermediary that provides quasi-public products. It is a tertiary industry cluster, which couples the productive economic activities. This type of service industry can be modelled in the light of the market demand. The productive service industries, i.e. the tertiary industry clusters, should be developed selectively and coordinated at all levels, such as to promote urban construction and industrial development in various aspects (e.g. production factors, corporate strategy, and demand conditions) (as shown in Figure 7 above).

The public service system is grounded on government-led supply chains, which are supplemented by social groups and private institutions. In the QMA, the public service system encompasses three layers: protection, promotion and selfdevelopment. The productive service industries interact and cooperate on these layers to achieve green growth of social economy (as shown in Figure 8 above).

(4) Vertical closed-loop industry chain based on ecological benefits

Here, an industrial chain is established for the GC development based on ecological benefits. In the industrial chain, the material flow, energy flow, water flow, waste flow and information flow of the enterprise were integrated through the matching of category, scale and orientation; the horizontally supply of products and exchange of by-products were also realized through the matching process. In this way, the secondary and tertiary industries were linked up into an industrial network. This network facilitates the exchange of material, energy and information, and improves resource utilization and material circulation, making it possible to establish an ecological industrial system.

(5) Regional integrated industrial chain of industrial clusters

The coupling of industrial clusters not only benefits the procurement, production, and distribution of a single industrial chain, but also formulates a network of various industrial chains with diverse service models [20]. Here, an industrial symbiosis network is constructed by integrating the characteristic enterprises in the QMA as per the industrial needs and conditions of the urban and rural areas. On this basis, a GC industry structure was established to realize the organizational extension of the circular industry. The components of the structure include water resources integration system, energy supply integration system, shared information integration system, ancillary facilities integration system, etc.

\subsubsection{Urban-rural sub-model}

The urban and rural areas provide the space and materials needed for GC development. The QMA is a highland of ecological capital in inland China. With 2,579 towns and 31,520 administrative villages, this area is featured by a low urbanization rate. For the GC development, it is inevitable for the QMA to integrate urban and rural areas.

In terms of spatial layout, the urban areas in the QMA (as shown in Figure 9 below) are distributed like belts or clusters, while the rural areas are distributed like belts or scattered as grids or branches. As shown in Figure 10, the spatial structure of the urban system in the QMA is very unbalanced. The spatial distribution of towns varies greatly from region to region. Some are aggregated as spots, while some are clustered as axes. The regional variation arises from the long-term combined effects of nature, human, and other factors.

The urban-rural sub-model offers three spatial development paths: the path for demonstration zones, the path for urbanrural integrated space, and the path for regional space. The space of demonstration zones constitutes a circular growth pole, which promotes the eco-environment in the peripheral areas. The urban-rural integrated space contains a circular growth pole and a number of circular axes, creating a living space with polarizing and radiating features. The regional space exhibits a gradient layout in structure.

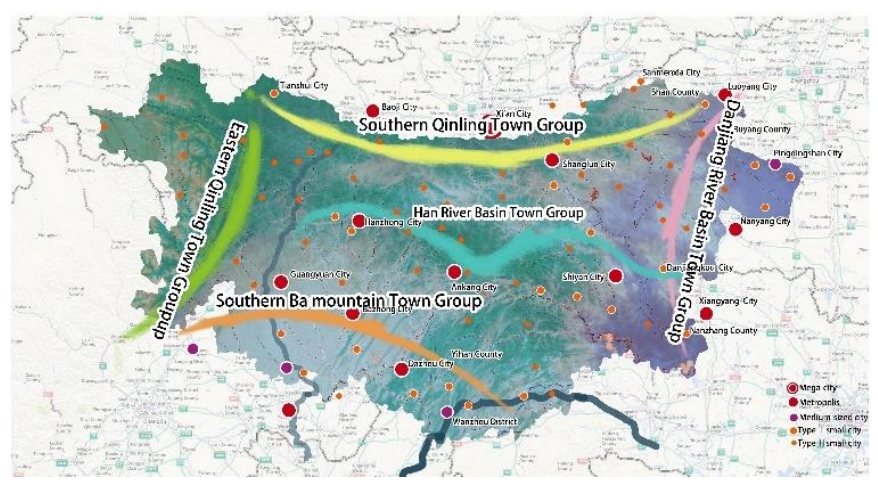

Figure 9. The spatial pattern of town clusters in the QMA 


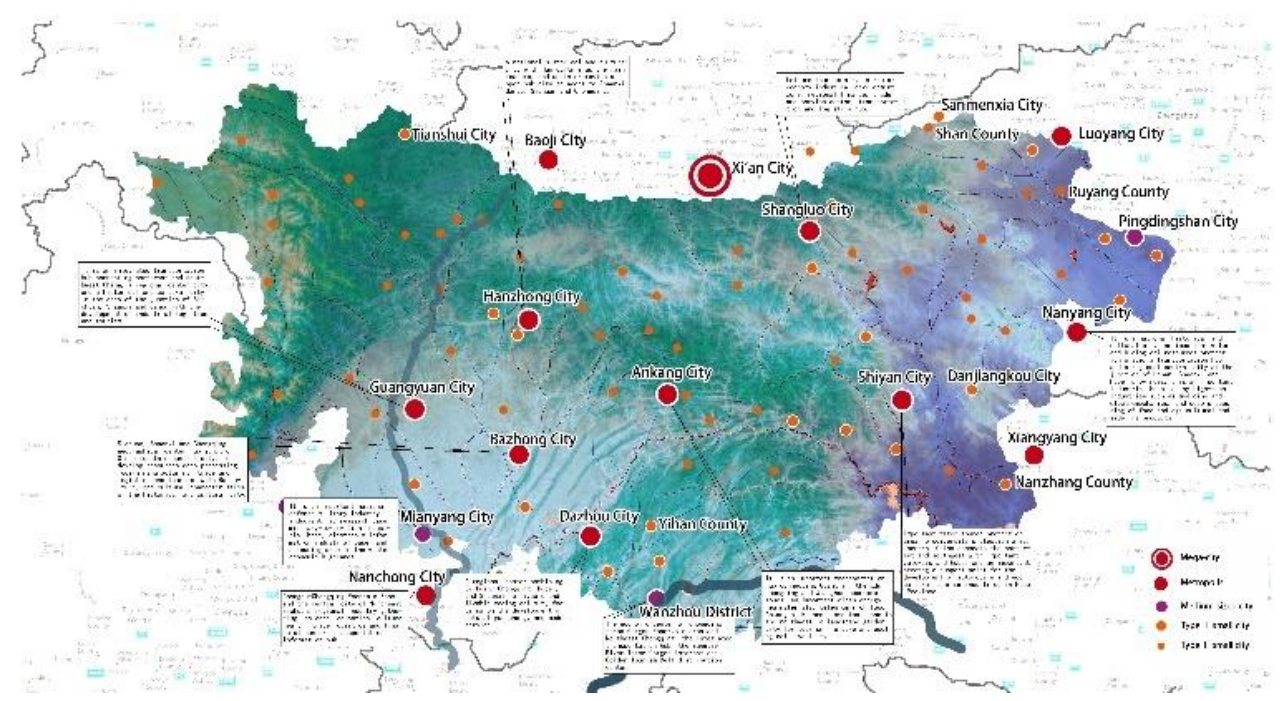

Figure 10. The spatial structure of the urban system in the QMA

(1) Chain development model of demonstration zones

In the demonstration zones of GC development, the industrial cooperation forms a complete industrial chain network through horizontal and vertical couplings. Each industrial function space is chained to the other spaces, according to its position in the industrial chain. Thus, a chain development model was created for the demonstration zones (as shown in Figure 11). Based on the natural and climatic conditions, this model can be implemented flexibly to make effective use of land, eliminating the mutual influence between industry and human activities.

(2) Cluster development model of urban-rural integrated space

The ultimate aim of the industrial economy is to develop regional economy as per resource advantages. Considering the layout of the tertiary industry, the urban-rural integration should focus on the existing cities, towns and villages. The key measures include improving the production service and public service related to the leading industry, embedding the secondary chain and mutually beneficial industry of the industrial chain system into the urban space, and forming a cluster-like spatial pattern (as shown in Figure 12). Under this cluster development model, the industrial space will grow steadily, the urban-rural coopetition will be enhanced, and the urban and rural areas will be developed in an integrated manner.

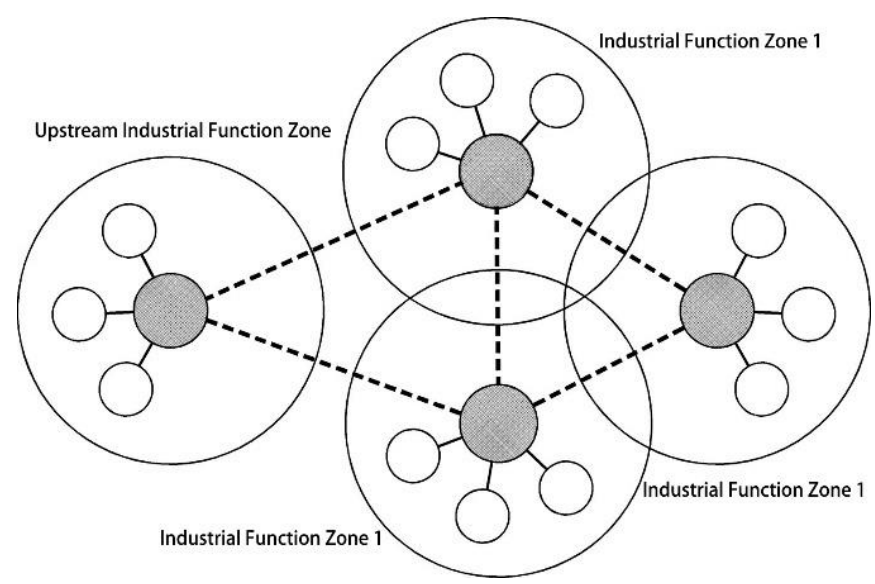

Figure 11. The chain development model of demonstration zones in the QMA

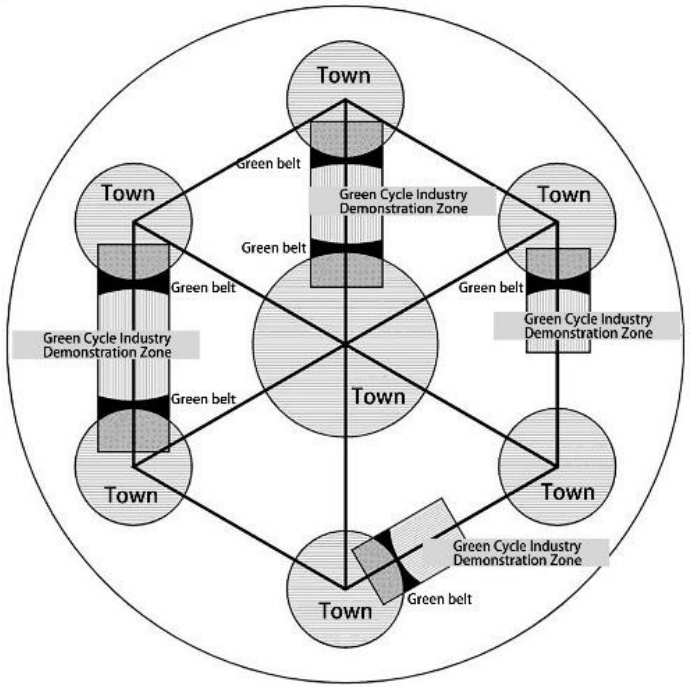

Figure 12. The cluster development model of urban-rural integrated space in the QMA

(3) Gradient development model of regional space

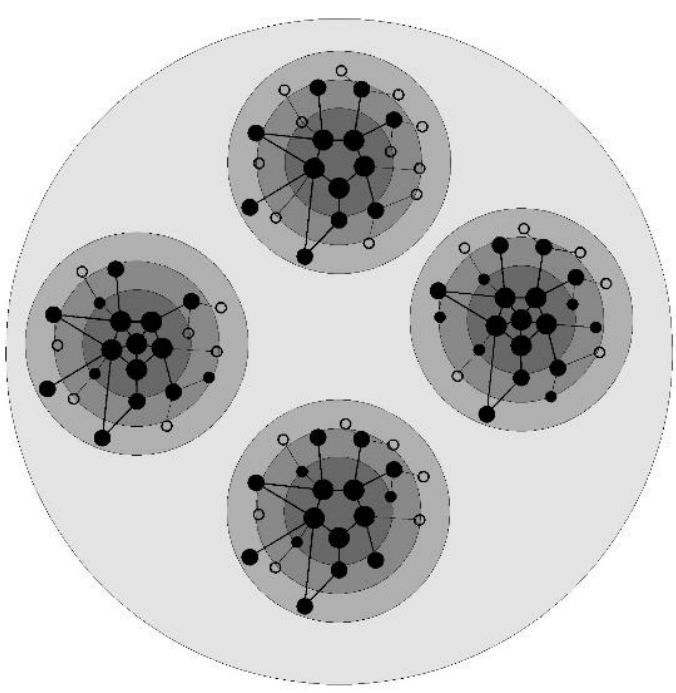

Figure 13. The gradient development model of regional space in the QMA 
By the principle of regional spatial interaction, socioeconomic objects will either diffuse or agglomerate in space [21]. For regional spatial development, ecological security must be taken as the top priority. Under this premise, the places occupied by characteristic industries should be rearranged into a gradient layout of industrial spaces that are uneven in development level. Efforts should be paid to construct micro-clusters in the demonstration zones of GC development, and to gradually form a gradient structure around the micro-clusters (as shown in Figure 13).

\subsubsection{Cross-regional sub-model}

As shown in Figure 14, the QMA covers two mountain ranges (the Qinling Mountains, and the Daba Mountain), spanning across six provincial administrative regions (Shaanxi, Sichuan, Chongqing, Henan, Hubei, and Gansu). In this area, there are six central cities (Xi'an, Lanzhou, Chengdu, Chongqing, Wuhan, and Zhengzhou) and five major urban clusters.

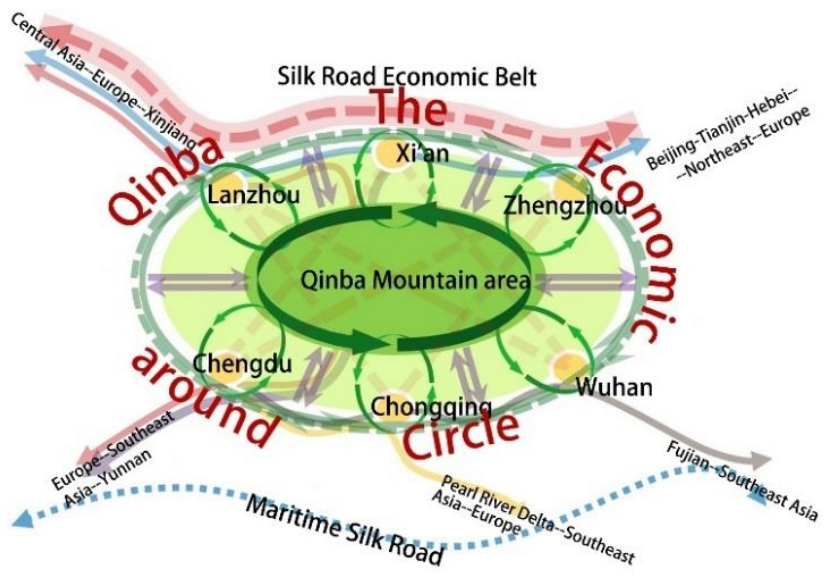

Figure 14. The cross-regional patterns in the QMA

There are two levels of the cross-regional GC development model: external collaboration and internal collaboration. The external collaboration focusses on the coordinated development between the central cities and the near field of the QMA. The near field collaboration relies on the construction of transport, market, and information networks. During the collaboration, the layout of the industrial clusters is adjusted continuously. Then, the urban-rural spatial structure is optimized in real time, resulting in the proper migration of population between urban and rural areas. To deepen the collaboration, the QMA should prioritize ecoprotection through collaborative management, governance and assessment, based on the joint operation mechanism of ecoprotection areas.

Guided by the industrial development model, the internal collaboration organizes the socioeconomic activities in the QMA into a feedback loop of resources, products, and renewable resources, through proper division of labour, systematic planning, and structural optimization. The industrial chain network should be integrated to create a number of urban micro-clusters, and construct the demonstration zones for the GC development, thereby promoting the health and sustainable development across regions.

3.2.4 The compound socioeconomic system in the QMA

Based on the above three sub-models, the authors established a compound socioeconomic system for the GC development in the QMA. As shown in Figure 15, the established system covers three key aspects: economic development, space construction, and mechanism guarantees. Grounded on the urban-rural sub-model, the compound socioeconomic system promotes the economy through the cross-industry sub-model, coordinates the supports to the GC development via the cross-regional sub-model, and ultimately builds a GC society in the QMA.

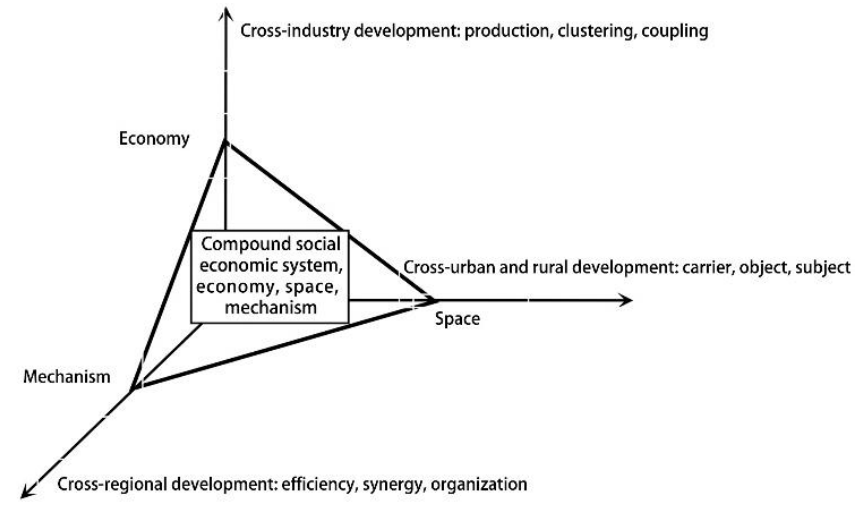

Figure 15. The compound socioeconomic system in the QMA

\section{CONCLUSIONS}

The GC development is the key for China to achieve a smooth transition of its development model. The QMA is the central reservoir, green lung, and mineral trove of China, and also a key area for poverty alleviation. The GC development of the QMA is crucial to the national security of China.

This paper firstly analyses the connotations of green development and circular economy, and summarizes the basic features of the GC development, revealing that the circular economy model and the balance between eco-protection and economic growth are conductive to the coordination between ecology, economy, and society.

According to the features of the QMA, the authors put forward a four-level (enterprise-industry-region-society) support system for the GC development in this ecological area, and built a GC development model consisting of three submodels: the cross-industry sub-model, the urban-rural submodel, and the cross-regional sub-model.

Specifically, the cross-industry sub-model, grounded on the basic trinity model, adopts overall development ideas of horizontal and vertical industrial chains, and creates an integrated industrial chain network for the QMA through horizontal coupling of secondary and tertiary industries and the vertical integration of industry chains based on ecological benefits.

The urban-rural sub-model specifies the integrated spatial development of urban and rural areas. The sub-model covers three dimensions, namely, the gradient development of regional space, the cluster development model of urban-rural integrated space, and the chain development of demonstration zones.

The cross-regional sub-model mainly consists of two levels of collaboration: the external collaboration and the internal collaboration. The former focuses on the collaboration and coordination between central cities in the QMA, while the 
latter aims to build various urban micro-clusters based on the industrial development model.

Finally, the three sub-models were combined into the compound socioeconomic system in the QMA, providing new insights into the GC development in the study area.

\section{ACKNOWLEDGMENT}

This study was supported by the 2020 Key research and development plan of Shaanxi Province (No. 2020SF-397).

\section{REFERENCES}

[1] Grimm, N.B., Faeth, S.H., Golubiewski, N.E., Redman, C.L., Wu, J., Bai, X., Briggs, J.M. (2008). Global change and the ecology of cities. Science, 319(5864): 756-760. https://doi.org/10.1126/science. 1150195

[2] Register, R. (1987). Ecocity Berkeley: Building Cities for a Healthy Future. North Atlantic Books.

[3] Zhou, N., He, G., Williams, C., Fridley, D. (2015). ELITE cities: A low-carbon eco-city evaluation tool for China. Ecological Indicators, 48: 448-456. https://doi.org/10.1016/j.ecolind.2014.09.018

[4] Xie, L., Flynn, A., Tan-Mullins, M., Cheshmehzangi, A. (2019). Water and land: Environmental governance and Chinese eco-development. Journal of Cleaner Production, 221: 839-853. https://doi.org/10.1016/j.jclepro.2019.02.204

[5] Wang, X., Mell, I. (2019). Evaluating the challenges of eco-city development in China: A comparison of Tianjin and Dongtan eco-cities. International Development Planning Review, 41(2): 215-242. https://doi.org/10.3828/idpr.2019.8

[6] Rudskaya, E.N., Eremenko, I.A., Yuryeva, V.V. (2019) Eco-cities in the paradigm of a circular economy and a comprehensive internet. IOP Conference Series: Materials Science and Engineering, 698(7): 077023. https://doi.org/10.1088/1757-899X/698/7/077023

[7] Xue, M., Dong, S.C., Li, Y. (2009). Comparative study of eco-city construction patterns at home and abroad. Urban Problems, (4): 71-75.

[8] Pang, M. (2017). Planning, transformation and development of resource based industrial cities. Open House International, 42(3): 88-92.
[9] Ma, L., Chen, J.N., Zhang, T.Z. (2004). Planning of ecocity according to circular economy principle - a case study of Guiyang City. China Population, Resources and Environment, 14(3): 54-56.

[10] Yu, X.H., Zhou, Q.H., Liu, P.D. (2016). Analysis on the current policy system of green cycle development in Qinba Mountain Area. Ecological Economy, 32(6): 129133, 178.

[11] Yu, X., Lin, G., Yang, R. (2016). Spatial pattern classification of agricultural-production rural settlements in Hanzhong area. Agro Food Industry Hi-Tech, 27(6): 113-118.

[12] Yu, X.H., Yang, R.H., Liu, B. (2018). Small valley urban spatial form in Hanjiang river basin. Open House International, 43(1): 11-15.

[13] Yu, X.H., Wang, X., Ren, Y.G., Liu, J.C. (2019). The landscape evaluation system of ecotourism villages in Qinling Mountains. Applied Ecology and Environmental Research, 17(4): 8955-8968.

[14] Lin, Y. (2008). How to promote the development of China's circular economy. Modern Economic Information, (5): 117.

[15] Li, Y., Dong, S.C., Wang, F., Wang, Z., Zhang, L.J. (2012). Study on development pattern and path of ecocity based on circular economy. Urban Development Studies, 19(11): 22-24.

[16] Zhang, P.P. (2015). A survey of domestic academic research on green development. Theoretic Observation, (4): 106-107.

[17] Qi, J.G. (2013). Circular economy and green development-human beings calling enhance vitality of the fourth technological revolution. Economic Review, (1): 43-53.

[18] Duan, J., Zhao, C. (2011). The practice of economic circulation in Gansu province is the exploration of green development road. 2011 China Forum on Sustainable Development, pp. 175-178.

[19] Gereffi, G. (1999). International trade and industrial upgrading in the apparel commodity chain. Journal of International Economics, 48(1): 37-70. https://doi.org/10.1016/S0022-1996(98)00075-0

[20] Wang, J. (2009). Development idea of logistics parks based on cluster regions. Urban Problems, (6): 21-24.

[21] Lu, D.D. (2001). An analysis of spatial structure and optimal regional development. Acta Geographica Sinica, 56(2): 127-135. https://doi.org/10.11821/xb200102001 